\title{
Synthesis and assessment of waste-to-resource routes for circular economy
}

\author{
Adrián Pacheco-López ${ }^{\mathrm{a}}$, Ana Somoza-Tornos ${ }^{\mathrm{a}, \mathrm{b}}$, Moisès Graells ${ }^{\mathrm{a}}$, Antonio Espuña ${ }^{\mathrm{a}, *}$ \\ a Department of Chemical Engineering, Universitat Politècnica de Catalunya, EEBE, C/ Eduard Maristany 16, 08019 Barcelona, Spain \\ ${ }^{\mathrm{b}}$ Renewable and Sustainable Energy Institute, University of Colorado Boulder, Boulder, CO, 80303, USA
}

\section{A R T I C L E I N F O}

\section{Article history:}

Received 12 January 2021

Revised 4 May 2021

Accepted 1 July 2021

Available online 7 July 2021

\section{Keywords:}

Circular economy

Material upcycling

Waste-to-resource

Ontologies

Chemical recycling

Plastic waste treatment

\begin{abstract}
A B S T R A C T
The benefits of the circular economy have been proven during the past two decades, but its application poses some challenges. In particular, the increasing number of potential waste-to-resource processing alternatives obstructs the identification of the most promising ones, besides the lack of efficient knowledge management tools and standardized assessment procedures. This contribution presents a systematic way to generate and assess new processing paths including waste-to-resource technologies, based on the use of a predefined ontological framework. An ontology is filled with transformation processes; then, several alternative paths are generated and assessed, according to a potentially available waste. The resulting list is classified according to pre-established parameters, thus presenting which are the potentially best alternatives to close the material loops and recover chemical resources. The proposed method is tested through the generation and evaluation of different routes for the treatment of plastic waste materials, with a special focus on chemical recycling.
\end{abstract}

(c) 2021 The Authors. Published by Elsevier Ltd. This is an open access article under the CC BY-NC-ND license (http://creativecommons.org/licenses/by-nc-nd/4.0/)

\section{Introduction}

In the last years, there has been an increasing concern about the degradation of the environment due to the large amount of waste generated by the constantly growing world population (Boix et al., 2015; Gu et al., 2020). In consequence, there is a rising awareness of the need to, not only treat waste but also convert it into valuable feedstock for other processes. This leads to counteracting the problem of plastic waste disposal, reduction of virgin material consumption, and conservation of resources, in alignment with the principles of the circular economy paradigm.

Promising processes for chemical recycling have been proposed in the direction of closing the loop of materials, but most of them are still in development at the lab scale (Ellen MacArthur Foundation, 2017). These processes are often disregarded, due to the lack of information on their cost, profitability, or performance at the industrial plant scale level. In order to assess if a technology is suitable for industrial scale, the Technology Readiness Level (TRL) has proven to be a useful indicator to assess the degree of maturity of an existing process (Solis and Silveira, 2020).

\footnotetext{
* Corresponding author.

E-mail address: antonio.espuna@upc.edu (A. Espuña).
}

Compared to traditional product-oriented processes, new challenges arise, such as identifying which is the best way to convert a specific waste stream into which added-value product(s) or feedstock(s), or which specific waste streams will offer better economic or environmental potential to be reused or recycled. Traditional methodologies may not be able to generate efficiently new alternatives or assess the constantly growing number of alternatives available in the literature to treat waste.

Consequently, there is a need to formalize current and future knowledge associated with waste-to-resource (W2R) transformations, as well as to efficiently integrate and exploit them, with the final objective of systematically generate and assess new W2R processing routes.

Furthermore, these potentially new W2R processes, resulting from the combination of existing processes and new ones operating in different conditions, should be assessed from the point of view of the different stakeholders involved, taking into account their different decision criteria.

The approach presented in this contribution relies on the use of ontologies as a knowledge modeling tool. Recently, ontology-based systems engineering has grown significantly to improve the Systems Engineering Body of knowledge (Yang et al., 2019).

Ontologies are most commonly defined as "a formal, explicit specification of a shared conceptualization" (Borst et al., 1997; 
Gruber, 1995; Studer et al., 1998). The definition can be broken down into three parts. "Formal, explicit" means that all the aspects of a described phenomenon are expressed in machine-readable language (not in natural language) and explicitly defined . "Shared" refers to the fact that an ontology reflects consensual knowledge; therefore, it should be shared by the community and no limited to individuals. "Conceptualization" refers to the abstract model to define a phenomenon.

In computer science, there are three principal types of usage for ontologies. The first one is to serve as libraries of knowledge to efficiently build intelligent systems. The second type is to serve as a reference of the shared vocabulary for human-computer intercommunication (Morbach, 2009). And the third type is to generate new inferred knowledge thanks to the use of inference-engines, also called reasoners, through the use of formal axioms (Corcho et al., 2006).

Ontologies can be modeled and implemented in various programming languages. In particular, most languages provide constructs for classes, individuals, relations, and attributes (Morbach et al., 2009). Among the available languages, the Web Ontology Language (OWL) is the most commonly employed for formal modeling of ontologies and describes precisely the semantics of classes, properties, and constraints (W3C OWL Working Group, 2012). OWL is a description logic-based language that eases the machine interoperability of knowledge.

A class represents a set of entities that share common features. Individuals are also known as entities, instances, or members that belong to a particular class. A relation represents the interaction between two classes, they are usually known as object properties. By definition, relations are unidirectional, which means that they go from a particular domain class to a designated range class. Attributes represent features, characteristics, or parameters of a class or an individual that are usually restricted to specific datatypes (Marquardt et al., 2010). These attributes are usually called data properties.

In addition to these basic elements, most languages allow the definition of axioms, which model propositions that are always valid. The definition of axioms allows greater expressiveness and formalizing knowledge beyond the simple existence of classes, individuals, attributes, and relations. Axioms are useful to explicitly define the semantics of a concept by imposing constraints on its values or interactions with other concepts, to verify the consistency of the ontology, and to infer new knowledge that is usually implicit (Marquardt et al., 2010). Usually, entities or relations that have been manually declared into the ontology are referred to as assertions, and those that are automatically inferred by a reasoner are inferences.

The extended use of ontologies has allowed the development of ontology-based engineering systems, providing a semantical environment and a knowledge management tool. Previous research has demonstrated the applicability of ontologies to circular economy and industrial symbiosis problems (Cecelja et al., 2015; Raafat et al., 2013; Zhou et al., 2018).

Two of the major goals any ontology needs to meet are usability and reusability. Usability refers to the degree to which it is useful for a specific task or application. No ontology is ready-to-use, so each one must be adapted to each specific application. Hence, the generic goal is to minimize "the effort required to customize the ontology so that it can be used by humans or machines in a given application context". On the other hand, reusability can be defined as "the adaptation capability of an ontology to arbitrary application contexts" (Paslaru-Bontas, 2007). Therefore, the goal of reusability is to ensure that the ontology can be adapted to a large number of applications.

Taking into account these requirements, as a starting point we selected an ontology that was based on these principles for its development and was specifically designed for the domain of Process Systems Engineering (PSE), which is OntoCAPE 2.0 (Marquardt et al., 2010). OntoCAPE is organized by means of three structural elements: abstraction layers, partial models, and modules. The abstraction layers, ranging in decreasing order of reusability and increasing order of usability are meta layer, upper layer, conceptual layer, application-oriented layer, and applicationspecific layer. Each module holds several interrelated concepts to a particular topic, and modules that address closely related topics are grouped into partial models. More specifically, a module assembles some interrelated classes, relations, and axioms, which jointly conceptualize the topic. Module boundaries are chosen such that each module can be used independently from the rest of the ontology up to some extent. A module may include other modules, and therefore OntoCAPE is organized as an inclusion hierarchy of loosely coupled modules (Morbach et al., 2009). For further information and a comprehensive description of the entire ontology refer to Marquardt et al., (2010).

\subsection{Problem statement}

The problem addressed in this work can be stated in the following terms: given a formal ontology for the domain of Process Systems Engineering, along with scientific documentation related to the domain of study, obtain a formal database with tentative processes suitable to manage a set of waste streams and transform them into usable resources.

Subsequently, given a set of characterized available wastes, potential product demands with quality requirements, and data assessment criteria to analyze the adequacy of the process to the given waste, the objective is to determine a ranked list of promising routes for the upcycling of materials, following economic, environmental and maturity objectives. This list contains alternatives aiming to close material loops and allowing the circular economy paradigm. Solving this problem allows a pre-selection of a finite set of alternatives that can be analyzed in-depth and optimized according to a given circular economy problem.

\section{Materials and methods}

The methodology used in this work is described in Fig. 1 and it is divided into two main tasks. The first one comprises the selection, adaptation, and instantiation of an ontology for the PSE domain with information retrieved from scientific documentation, as well as estimated data if it is not available, obtaining then a set of processes suitable for the domain of study (c.f. Section 3.1). The second task consists in developing an algorithm that, starting from the potential transformation processes available in the ontology, implicitly builds a superstructure, and selects those alternatives that are more promising from the economic and environmental point of view. With the alternatives created in the previous step, an assessment procedure is performed in which the alternatives are weighted and sorted accordingly based on pre-established criteria, as developed below in section 3.2.

As introduced before, processes information has been retrieved from scientific documentation through an exhaustive and systematic literature review. This review has been conducted by searching on the main scientific databases, selecting a set of documents related to the domain, and extracting all useful information that is then asserted in the ontology as processes or materials instances. This information involves data for the process performance, such as feed characterization, capacity, yield, temperature, as well as economic data such as product prices or process costs, and environmental footprint information. It is important to remark that all calculations and data are based on 1 ton of initial waste. 


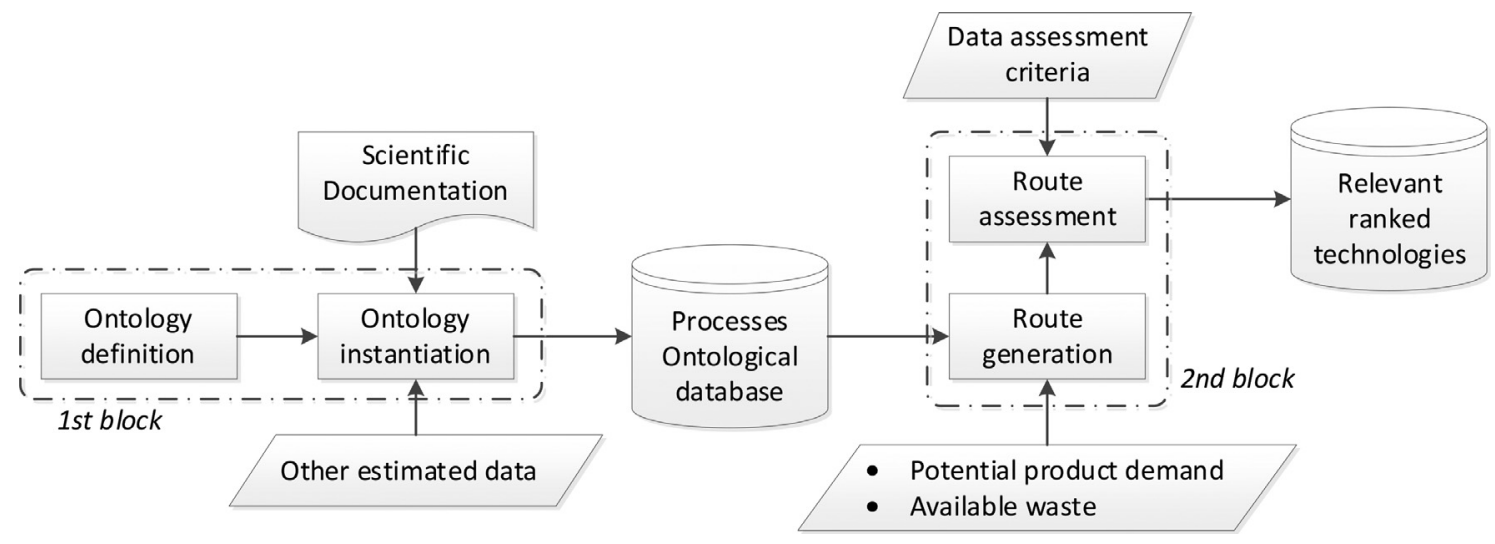

Fig. 1. Methodology description.

As observed in most cases, there is not much information available about economic and environmental performance for processes on early steps of development, in consequence, this information has to be estimated or calculated. For that purpose, in this work we are using the estimations and calculations developed in previous works by Somoza-Tornos et al., (2021).

\subsection{First block: ontology selection, adaptation, and instantiation}

An ontological framework is used to model resources, waste, and potential transformation technologies considering their composition, characteristics, and other relevant specifications. These specifications are mainly: process inputs and outputs, capacities, yields, outlet quality or purity, process cost (or enough information to estimate it), LCA endpoint or midpoint indicators other parameters such as type of process, temperature, pressure...

First, the set of transformation processes available in the domain of study is identified, characterized and manually entered into the ontology framework. These transformation processes have to be well defined: the relevant parameters should be available in the ontology, otherwise missing parameters should be estimated according to relevant recommended procedures.

For the management and adaptation of the ontology, we are using the Protégé ontology editor (Musen, 2015), which includes the reasoner HermiT, (Glimm et al., 2014) that can be used to validate the consistency of the ontology and infer new relations between concepts that were not previously asserted, therefore saving time when adding information.

The chosen ontology framework is a modified version adapted from OntoCAPE (RWTH Aachen University, 2016). The ontology files (which are referred to as formal specifications) were obtained from the source website, where they are available under the terms of GNU General Public License along with six technical reports, also known as informal specifications. Consequently, the ontology files are modified to fit the current application.

OntoCAPE can be characterized as a formal heavyweight ontology, which is represented in the OWL modeling language, and more specifically OWL-DL (Bechhofer et al., 2004). It consists of several sub-ontologies with different functions, and more precisely, it consists of 62 OWL files, each one including one module of the ontology.

As mentioned above in Section 1, OntoCAPE is organized through layers, partial models, and modules. Layers divide the ontology into different levels of abstraction to separate general knowledge from knowledge about a particular domain or application. The Meta Layer is the most abstract one and introduces fundamental concepts and design guidelines for the ontology construction. The Upper Layer defines the principles for the organization of the ontology. The Conceptual Layer conceptu- ally models the CAPE domain in different areas such as unit operations, equipment, materials, chemical process behavior, simulation... The Application-Oriented and Application-Specific Layers extend the ontology towards general or specialized applications (Morbach et al., 2009). This last layer is not necessary for this work and it is consequently omitted.

We use the nomenclature as reported by the OntoCAPE specifications; we also follow the original structure of the ontology for all the added concepts such as modules, instances, and relations. Since the ontology encompasses a wide range of concepts and levels useful for most PSE applications, we need to tailor it to adapt it to our work and discard irrelevant data. For that reason, some partial models, modules, and layers have been omitted from the original ontology, and only the essential ones remain. The main modifications and additions performed in the ontology are detailed below, and the resulting structure of the modified ontology can be seen in Fig. 2.

Since the process description is needed at a conceptual level, we are using the top layers of the ontology up to the conceptual layer. Within this level of abstraction, one of the most important partial models in the ontology is the so-called chemical_process_system, given that it is the key partial model in the ontology and addresses the body of knowledge on the chemical engineering discipline. It is also intended to provide a complete coverage of the high-level concepts within the domain (Marquardt et al., 2010).

We are using the partial model CPS_Function for process description, which deals with the functional description of the chemical_process_system model. CPS_behavior, which consists of the phenomenological description of the processed material amounts. Finally, the CPS_performance model, which is applied to the evaluation of the process from the economic and environmental point of view.

We also include two other partial models within the conceptual layer. The models supporting_concepts, which holds essential concepts for the description of any process, such as physical dimensions or space and time concepts, and material, that includes details of the substances involved in the chemical transformations.

It is important to remind that partial models and modules inside of upper and meta layers are required, since they introduce key concepts that are specialized on the lower layers and they define the base for topological and mereological relations between entities.

According to these premises, processes are asserted in the ontology within the class "ProcessStep", where they are classified in subclasses depending on the kind of process, specifically: unit operations (separation, combination, enthalpy change...), reaction, and aggregated process steps. On the other hand, connections between different processes are classified as "ProcessStates", and fur- 


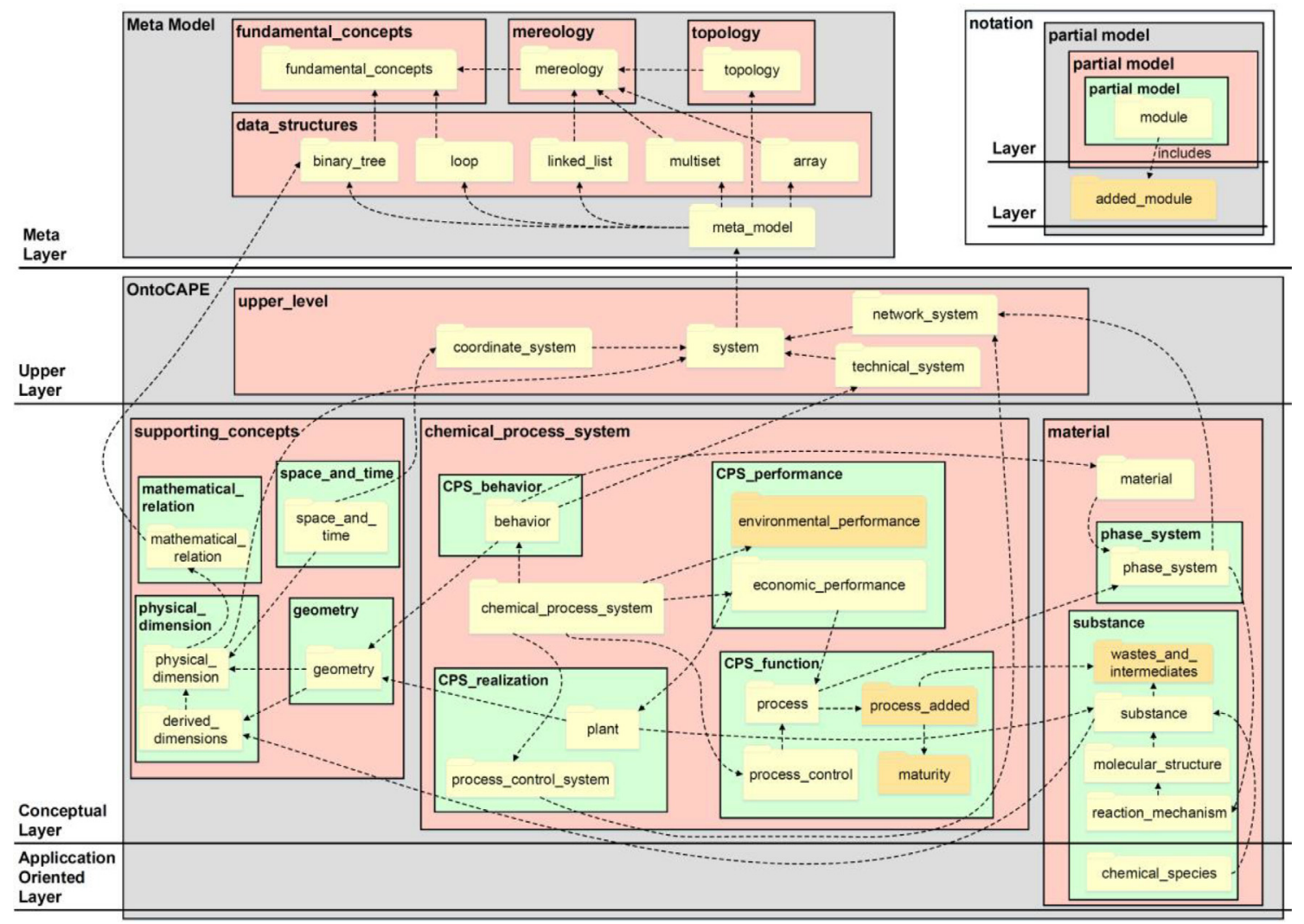

Fig. 2. Modified OntoCAPE structure, adapted from (Morbach, 2009). Modules in orange are new; modules in yellow remain from the original structure of the ontology.

ther classified in subclasses such as raw materials, intermediate products, and output products. See Figs. 3 and 4 for more details about the classification and hierarchy of instances in the ontology. The entities that are classified according to Fig. 3 are related to those from Fig. 4 through some relevant properties, this fact is exemplified in Fig. 5. These relations are known as object properties and they are links between objects. It is important to remember that these properties or relations are inherited, i.e. the relations between two classes are also valid for their subclasses. For further details on the structure of the ontology we recommend referring to the OntoCAPE book (Marquardt et al., 2010).

Most of the newly added classes and instances are created within auxiliary ontologies that are imported by other already existing ontologies, and the original ontologies from OntoCAPE remain unchanged. By doing so, we avoid making undesired changes in the original files and possibly adding inconsistencies into the ontology.

The only original files where the instances are directly added are economic_performance and behavior. In the first one, process costs and material prices are added to their corresponding classes as instances; in the latter, the generalized amounts of all process states concerning the initial waste, i.e. the yield ratio of each output process state, are included.

The processes asserted in the ontology are added in a new module called process_added, which is imported by the original module process. The wastes to treat and all the possible intermediate products are located in the module wastes_and_intermediates. The Technology Readiness Level (TRL) values are added to the module maturity.

In the informal specifications for OntoCAPE, a module for environmental impact is suggested within the CPS_performance partial model, but it was not implemented in the latest available version of the ontology, which only considers economic performance.
Following the same structure as the economic_performance module, we created the module environmental_performance and the corresponding classes and properties for the respective environmental indicators.

\subsection{Second block: route generation and assessment}

In order to connect the available wastes with the final marketable products, an input-output matching method is applied, thus being able to generate different process paths (or routes) with their eventual outcomes and taking into consideration tentative intermediate products, which will enforce specific sequencing constraints.

Finally, end-of-life treatment processes for any non-marketable by-products, such as incineration for energy recovery or landfill, are included in the proposed process network if necessary.

The method is developed through an algorithm written in Python 3 language (Van Rossum and Drake, 2009). The algorithm sequentially performs all the steps of this methodology, starting with importing the ontology into the programming environment. Once the ontology is imported, using an input command, the user selects a waste, from those available in the ontology. After this step, the algorithm opens a loop where the input-output matching is performed and the network with all possible routes is built. Next, we obtain all single paths that range from the starting node to all possible final nodes, which are then assessed taking into account their economic and environmental performance as well as maturity considerations, and finally, the paths are sorted from the most promising to the least.

\subsubsection{Database querying}

First, we need to import all the possible processes from the ontology connecting waste sources with tradable products. For 


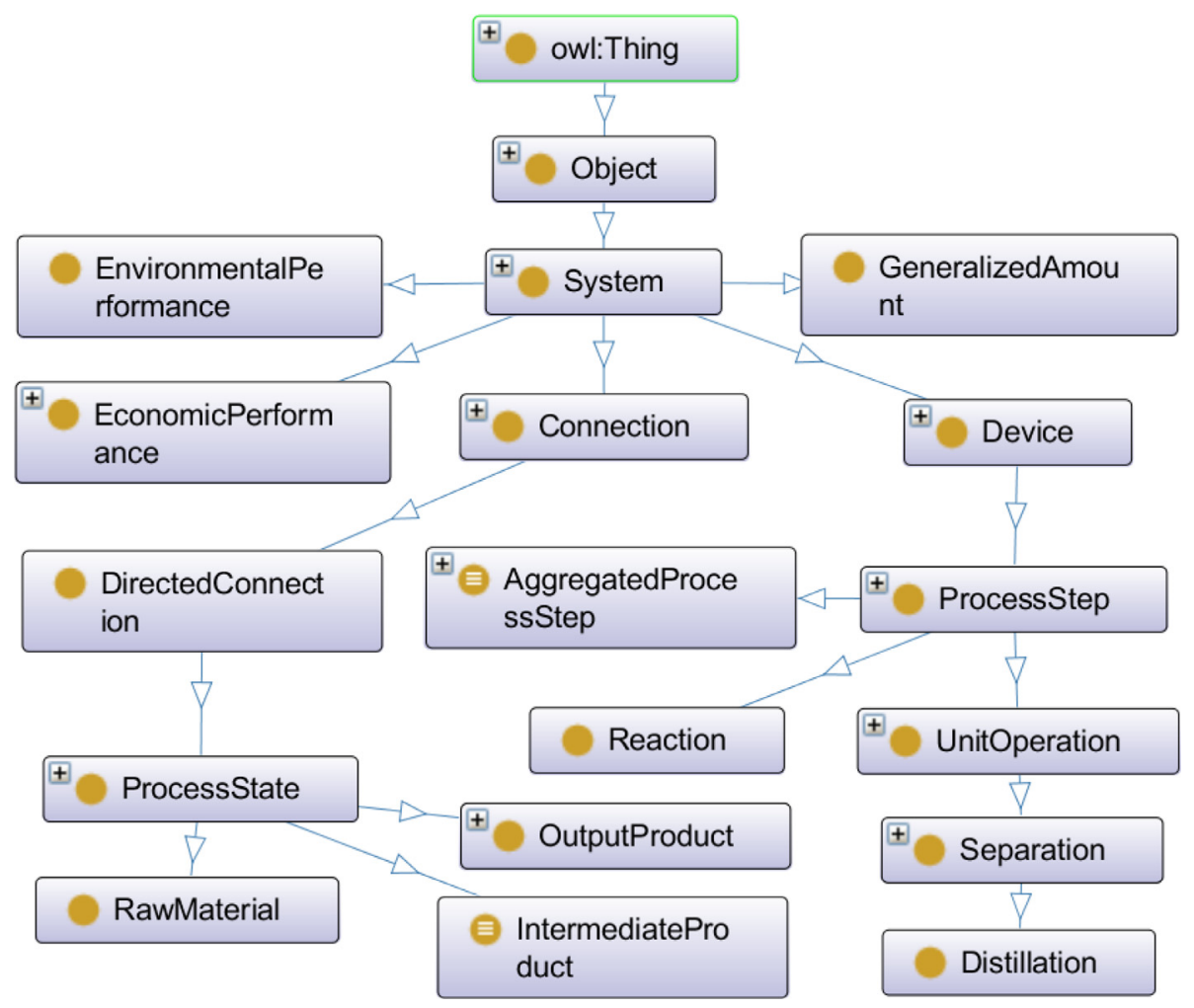

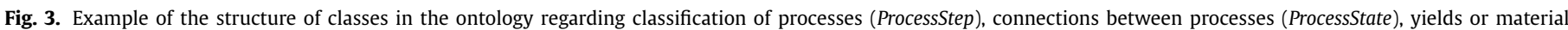

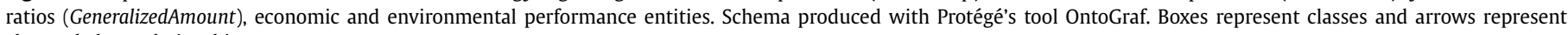
class-subclass relationships.

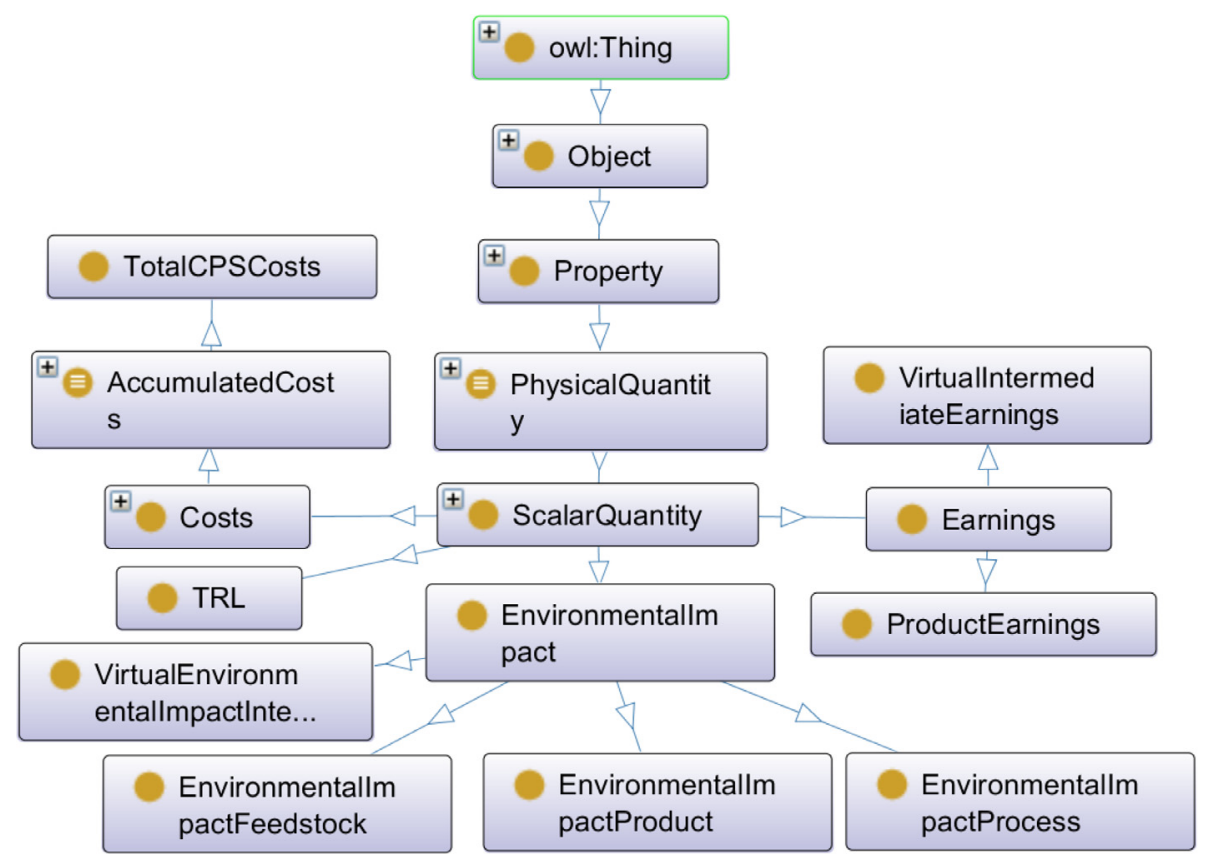

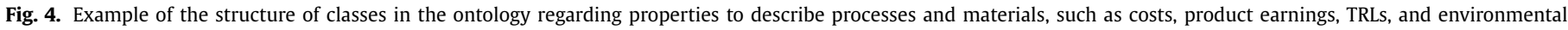
impacts. Schema produced with Protégé's tool OntoGraf. Boxes represent classes and arrows represent class-subclass relationships.

the integration of the ontology and the algorithm, an ontologyoriented interface is needed. We use an object-oriented programming tool for accessing entities from OWL ontologies, namely an Open-Source software called Owlready2 developed in Python by Lamy (2017). This tool enables, not only an easy access to all information available in the ontology, such as entities and relations between them but also systematically adding new information, and running a reasoner for the inference of new missing relations or the discovery of possible conceptual inconsistencies.

The query procedure takes advantage of the fact that information is stored in the ontology in form of axioms. For instance, if we want to obtain the outputs (categorized within ProcessState class) 


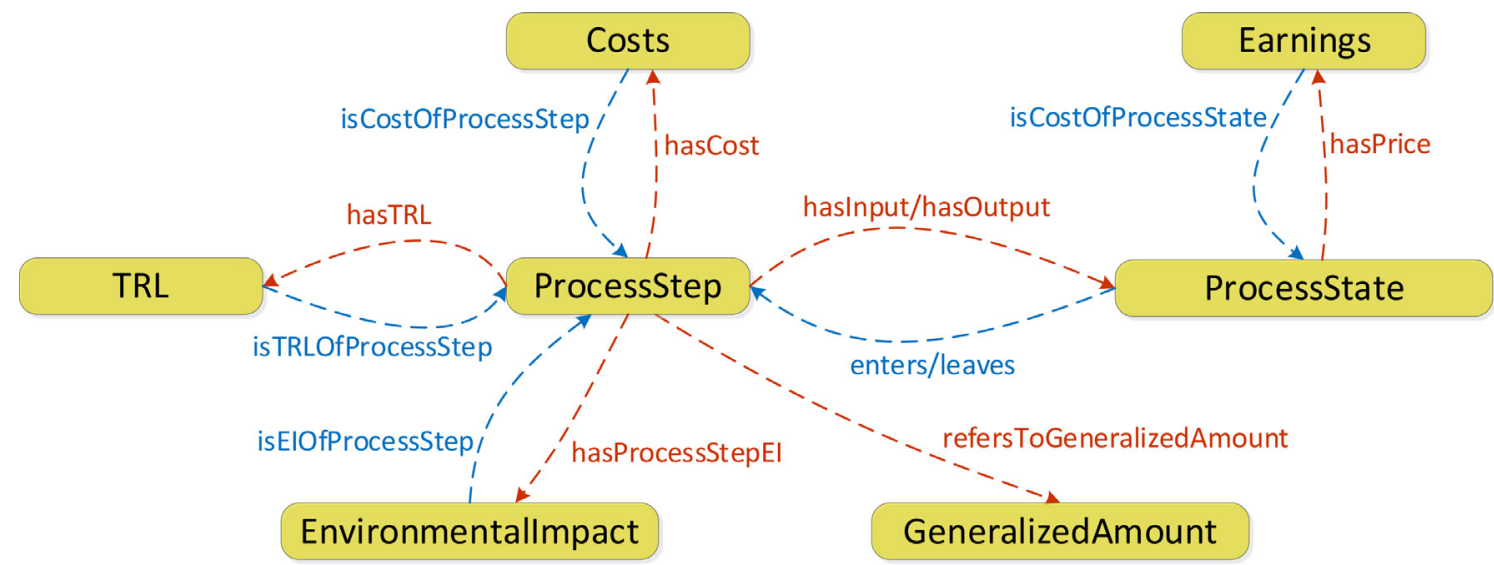

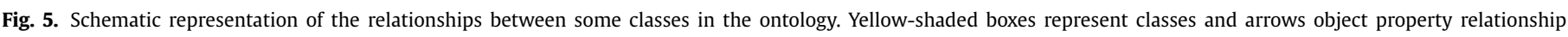

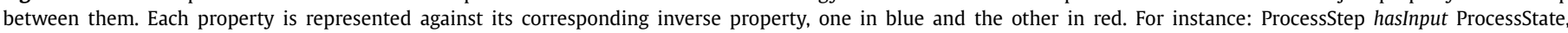
therefore ProcessState enters ProcessStep.

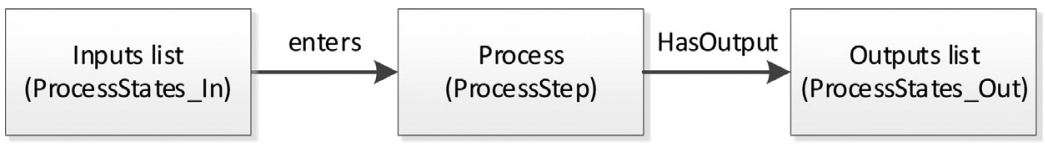

Fig. 6. Description of the process structure in the ontology.

of a particular process (ProcessStep class), the query would be as follow:

Query >> Process1.hasOutput

Answer: [Output1, Output2, ..., OutputN]

This answer of the program is possible thanks to the ontology axioms that organize information with the following structure:

Axiom_1: Process1 hasOutput Output1

Axiom_2: Process1 hasOutput Output2

Axiom_N: Process1 hasOutput OutputN

The same procedure is followed to access data properties that hold numerical information in the ontology, for example: costs, environmental impacts, or TRL values. For instance, if we need a cost value for a particular process, we need to query first for the instance where the cost is asserted and then for its value (which a defined data property in the ontology):

Query >> Process1.hasCost.value

Answer: $100.0 \mathrm{f}$ (f is for float)

The network construction method described below is based on this querying procedure to access the information stored in the ontology.

\subsubsection{Network construction and analysis}

With the ontology already imported, we can query about any entity or relation between them, as well as accessing any kind of data stored in it, which is an essential step for the network construction explained below. Using the querying procedure mentioned above, a graph is built, whose interconnected nodes correspond with process steps and process states, as they are known in the ontology.

An input-output matching algorithm is developed to connect wastes, processes and products. Taking into account the process structure illustrated in Fig. 6, the algorithm links each material stream with each one of their tentative processes (see Fig. 7). The graph is built in stages, that is, parting from a waste (ProcessState), the ontology is queried to find which processes (ProcessSteps) have that ProcessState as input. With another query, all the outputs of each one of these ProcessSteps are obtained and the procedure is repeated with each one of the ProcessStates, building branches that will end when a ProcessState cannot be further treated to obtain a marketable product or the ProcessStep does not have any output, which means it is an end-of-life alternative.

Accordingly, a tree-like graph with all the possible branches is built using a state-task network approach as defined by Kondili et al. (1993), where operations and processes are considered as "tasks" and feedstock, intermediate and final products as "states". This representation can be classified as a bipartite graph, which has two kinds of nodes, one for processes (considered in the ontology as "ProcessSteps") and another for materials (considered as "ProcessStates"), which are connected through edges. At this level, the graph stores information about economic, environmental, and behavioral aspects in its nodes as well as the interconnection between nodes, but no routing or path finding is performed yet.

Once the graph is implicitly built, the algorithm builds all single paths rooting from the initial node, which is the waste to treat, towards all tentative final products. The algorithm is adapted to allow the completion of a limited number of paths for an easier further assessment attending to the total profit values of each path.

\subsubsection{Route assessment}

The process characteristics to be assessed are sorted into three main categories: economical, environmental, and maturity. For each one of the transformation routes previously created, a ponderation method is applied to sort them out, seeking the maximum economic and environmental profit, as well as promoting the use of simpler and more mature processes.

In order to calculate the performance of each path, an economic balance (economic profit) is first calculated for each single process step Eq. (1), the same is done with the monetized impact (environmental profit, Eq. (2)). For each processing path generated, a total economic and environmental profit are calculated Eqs. (3), (4). Finally, for each processing path, a total profit is obtained adding economic and environmental profits Eq. (5)). Additionally, weighting factors are calculated to prioritize paths with higher economic and environmental profits against those with lower values (Eqs. (6), ((7)). Another factor is calculated with the TRL values to give preference to the use of more mature technologies, as seen in Eq. (8). Note that the set $i$ refers to the process steps set, $j$ to 


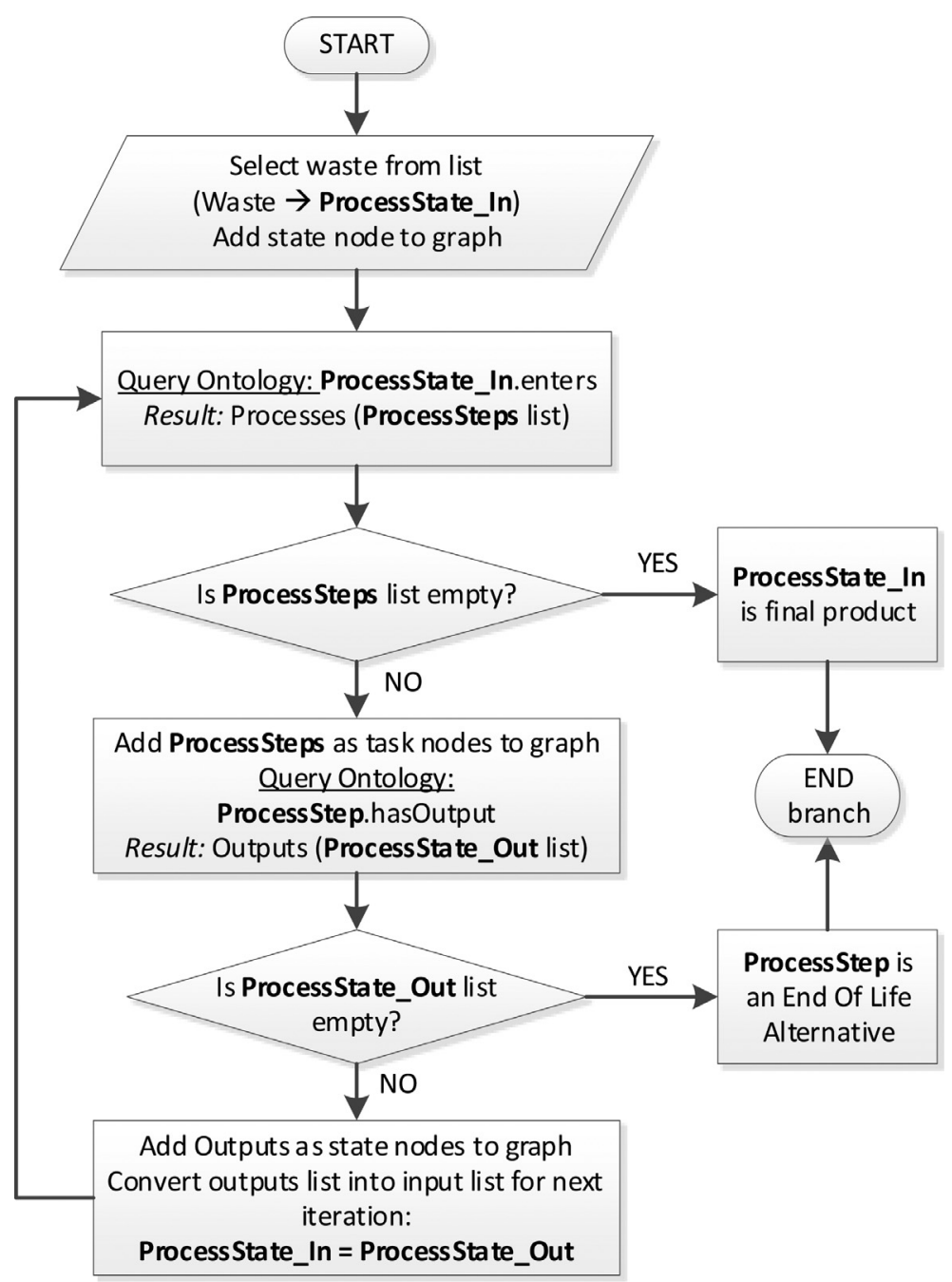

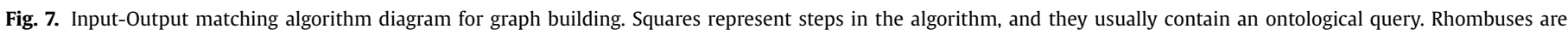
checkpoints to devise where to stop querying and terminate a particular branch.

the process states set, and $k$ to the set of full paths.

Profit $_{i}^{\text {eco }}=\sum_{j \in \text { outputs }} x_{i, j}^{\text {out }} \cdot$ Price $_{j}-\sum_{j \in \text { inputs }} x_{i, j}^{\text {in }} \cdot$ Price $_{j}-$ Cost $_{i}$
Profit $_{i}^{\text {env }}=\sum_{j \in \text { outputs }} x_{i, j}^{\text {out }} \cdot E I_{j}^{\text {p.state }}-\sum_{j \in \text { inputs }} x_{i, j}^{\text {in }} \cdot E I_{j}^{\text {p.state }}-E I_{i}^{\text {p.step }}$

Profit $_{k}^{\text {eco,path }}=\sum_{i \in \text { path }_{k}}$ Profit $_{i}^{\text {eco }}$

$\operatorname{Profit}_{k}^{\text {env,path }}=\sum_{i \in \text { path }_{k}}$ Profit $_{i}^{\text {env }}$

Profit $_{k}^{\text {total,path }}=$ Profit $_{k}^{\text {eco,path }}+$ Profit $_{k}^{\text {env,path }}$

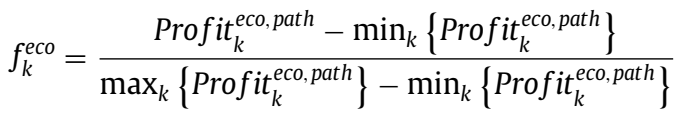

$f_{k}^{\text {env }}=\frac{\text { Profit }_{k}^{\text {env,path }}-\min _{k}\left\{\text { Profit }{ }_{i}^{\text {env,path }}\right\}}{\max _{k}\left\{\text { Profit }_{k}^{\text {env,path }}\right\}-\min _{k}\left\{\text { Profit }_{k}^{\text {env,path }}\right\}}$

$f_{k}^{T R L}=\frac{T R L_{k}-\min _{k}\left\{T R L_{k}\right\}}{\max _{k}\left\{T R L_{k}\right\}-\min _{k}\left\{T R L_{k}\right\}}$
Finally, a global performance indicator (GPI) is calculated for each path as shown in Eq. (9), which sorted in decreasing order, that is to say, the routes with the greatest GPI are at the top of the list and the ones with the lowest at the bottom. The multiplication of the total profit by each one of the factors will allow promoting alternatives with better economic and environmental performance along with the degree of development (TRL) and penalizing those with a poor performance in any of the three categories. This fact allows differentiating and maximizing the gaps between alternatives, those with similar performance in one category but worse in the others, from those with better average performance in all categories. For instance, if a technology has very good economic performance, but its environmental performance is the lowest among all technologies, the GPI would automatically be zero, since the environmental factor would be zero (according to the factor calculated with Eq. (7)). For that reason, this technology would be disregarded. On the other hand, if two technologies have similar economic performance, the differences in their environmental performance and/or degree of development act as a discriminating factor between them, and promoting the one with higher values.

$G P I_{k}=$ Profit $_{k}^{\text {total,path }} \cdot f_{k}^{\text {eco }} \cdot f_{k}^{\text {env }} \cdot f_{k}^{T R L}$ 


\section{Case studies}

Among the different types of human generated residues, plastic waste deserves special attention, since they are amid the most abundant and lasting types of waste, they come from materials whose production have required significant quantities of resources, and usually they have had a very short average lifespan.

From the $14.55 \mathrm{Mt}$ of plastic post-consumer packaging waste collected in 2018 in the EU (Eurostat - European Commission, 2020), only $42 \%$ was sent to recycling, while $39.5 \%$ was used for energy recovery and $18.5 \%$ was discarded to landfill (PlasticsEurope, 2020). Thus, waste accumulation and resources depletion concerns are set to grow in the next years due to the lack of effective and efficient resource and waste management policies in most countries worldwide. The chemical recycling of plastics offers a solution through more efficient waste management and material upcycling, leading to economic and environmental benefits (Jeswani et al., 2021; Martín et al., 2020; Somoza-Tornos et al., 2020b).

There have been efforts towards model development to find optimal solutions for the treatment of the available plastic waste. Pyrolysis, for instance, is a tertiary recycling technology that offers recovery of material quality, leading to raw material production and supporting the current ambition for closing the loop on plastics (Al-Salem et al., 2017). In addition, plastic waste offers high potential as a source for chemicals and fuel production (Singh et al., 2017).

In 2004, Kaminsky et al., studied the pyrolysis of several plastic wastes for monomer recovery, using an indirectly heated fluidized bed (Hamburg process) at different temperatures. Onwudili et al. (2009) investigated the effects of reaction temperature and residence time for the pyrolysis of LDPE and PS and their mixtures over a temperature range from 300 to $500^{\circ} \mathrm{C}$, in a closed batch reactor. The effect of temperature over the yield of gaseous olefins through flash pyrolysis of waste PE at lab-scale was studied by Kannan et al. (2014), finding that the yield of ethylene in- creases with temperature, reaching nearly $50 \%$ around $1000^{\circ} \mathrm{C}$. The catalytic pyrolysis of a plastic mixture was simulated by Onwudili et al. (2019) to determine optimal conditions for the upcycling of municipal solid waste, obtaining valuable products such as LPG, premium fuel range $C_{5}-C_{15}$ hydrocarbons or aromatics compounds, at temperatures around $600^{\circ} \mathrm{C}$ using zeolite catalysts.

These are a few examples of the development towards plastic waste chemical recycling studied and developed recently. However, the selection of the most promising or profitable alternatives for materials upcycling becomes complex due to the constantly increasing number of choices available. Hence, our tool to systematically generate and assess new potential pathways seeks to offer a pre-screening of the most promising and profitable alternatives, based on an exhaustive literature review and efficient knowledge management tools, as a previous step to further detailed superstructure analysis and optimization.

To illustrate the methodology, we have tested it on two case studies about the chemical recycling of plastic waste based on the one developed by Somoza-Tornos et al., (2021). The first case study is a motivating example for the treatment of polyethylene waste (PEw). The second one includes a set of waste-to-resource processes to upcycle mixed plastic waste (MPW), which encompasses mainly polyethylene waste (PEw), polypropylene (PPw), polystyrene (PSw), and polyethylene terephthalate (PETw). Landfilling and incineration for energy recovery are considered as end-of-life alternatives for waste that cannot be upcycled. We have extended the list of alternative recycling routes by including mechanical recycling and direct downcycling. Refer to SomozaTornos et al. (2021) for specific details on the methods to calculate the economic parameters and environmental impacts for the base case.

Regarding direct downcycling, we assume that the price of plastic waste is unchanged and the process cost is null. The same assumption is done for the environmental indicators of both, processes and products. Below, we include the assumptions for the calculations of the extended information:

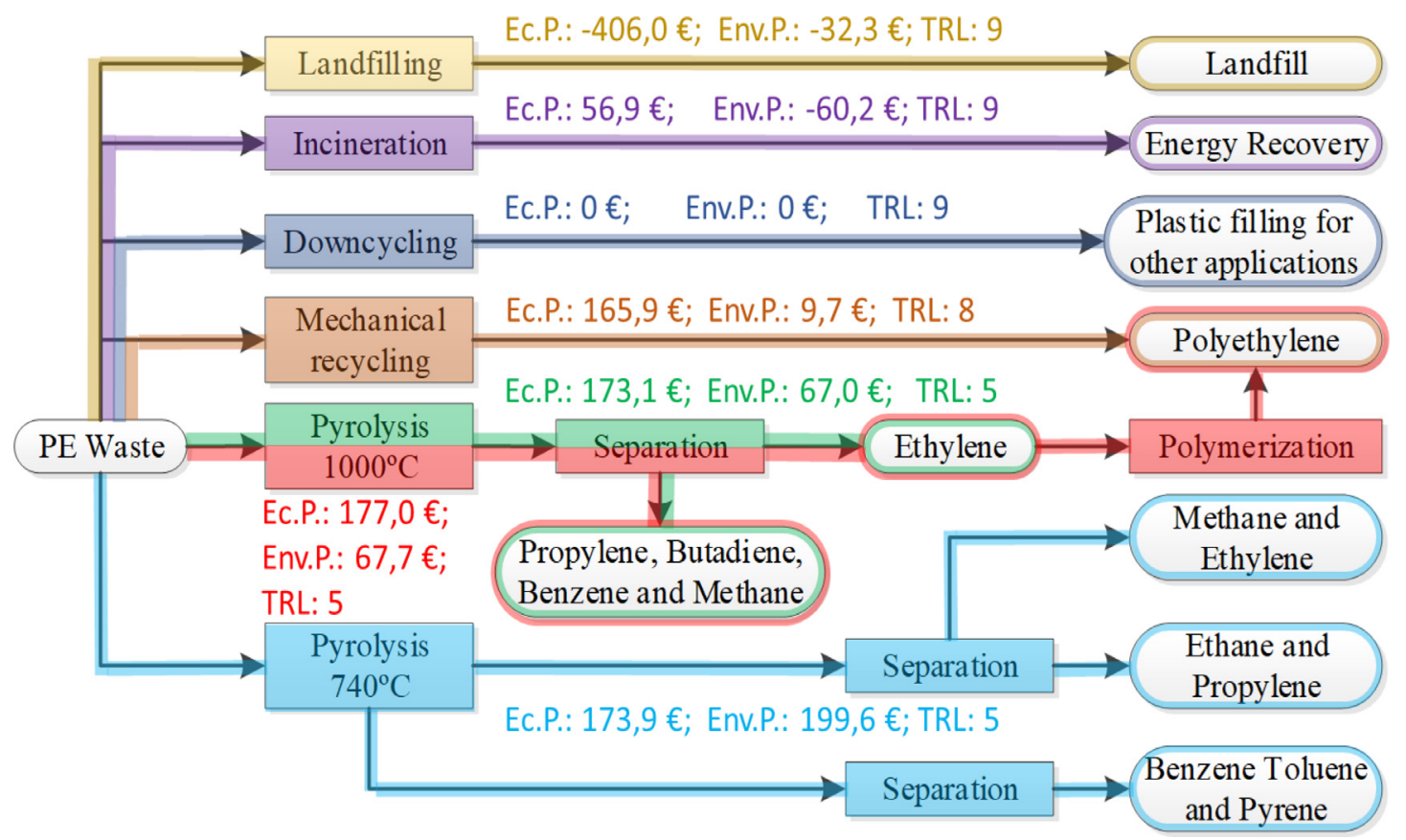

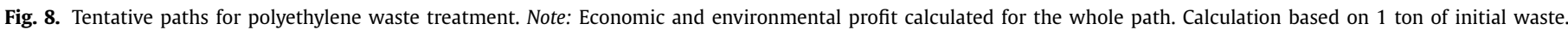

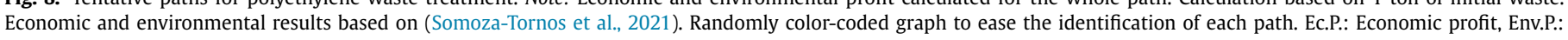
Environmental profit. 
Table 1

Deployed process paths with their corresponding outputs for polyethylene waste treatment. S.: Separation, P.: Polymerization, Pyro.: Pyrolysis. Source: (Somoza-Tornos et al., 2021).

\begin{tabular}{lll}
\hline Path & Processes & Outputs \\
\hline 1 & Landfilling & None. \\
2 & Incineration & Energy recovery. \\
3 & Downcycling & PE Waste. \\
4 & Mech. recycling & Recycled grade PE. \\
5 & Pyro. $1000^{\circ} \mathrm{C}+\mathrm{S}$. & Butadiene, benzene, ethylene, methane \& propylene. \\
6 & Pyro. $1000^{\circ} \mathrm{C}+\mathrm{S} .+\mathrm{P}$. & Butadiene, benzene, PE, methane, propylene \& energy recovery. \\
7 & Pyro. $740^{\circ} \mathrm{C}+\mathrm{S}$. & Ethylene, ethane, methane, propylene, pyrene, benzene \& toluene. \\
\hline
\end{tabular}

Table 2

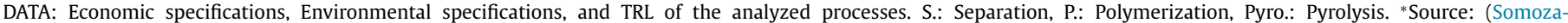
Tornos et al., 2021).

\begin{tabular}{|c|c|c|c|c|c|c|c|c|c|}
\hline \multirow[b]{2}{*}{ Process path } & \multicolumn{4}{|c|}{ Economic specifications ( $€ /$ ton of waste $)^{*}$} & \multicolumn{4}{|c|}{ Environmental Value ( $€ /$ ton of waste)* } & \multirow{2}{*}{$\begin{array}{c}\text { TRL } \\
\text { Value }\end{array}$} \\
\hline & Total cost & Waste purchase & Products value & Profit & Process & Feed & Products & Profit & \\
\hline Pyro. $740^{\circ} \mathrm{C}+\mathrm{S}$ & 216.6 & 308.0 & 698.5 & 173.9 & 79.3 & 13.2 & 292.1 & 199.6 & 5 \\
\hline Pyro. $1000^{\circ} \mathrm{C}+$ S. + P. & 320.6 & 308.0 & 805.6 & 177.0 & 141.4 & 13.2 & 221.6 & 67.0 & 5 \\
\hline Pyro. $1000^{\circ} \mathrm{C}+\mathrm{S}$ & 214.5 & 308.0 & 695.6 & 173.1 & 104.5 & 13.2 & 185.5 & 67.7 & 5 \\
\hline Mechanical Recycling & 106.7 & 308.0 & 580.5 & 165.9 & 140.7 & 13.2 & 163.6 & 9.7 & 8 \\
\hline Direct Downcycling & 0.0 & 308.0 & 308.0 & 0.0 & 0.0 & 13.2 & 13.2 & 0.0 & 9 \\
\hline Incineration & 128.2 & 308.0 & 493.1 & 56.9 & 209.3 & 13.2 & 162.4 & -60.2 & 9 \\
\hline Landfilling & 97.5 & 308.0 & 0.0 & -405.5 & 19.1 & 13.2 & 0.0 & -32.3 & 9 \\
\hline
\end{tabular}

Table 3

Results and weighting parameters for the different process paths. S.: Separation, P.: Polymerization, Pyro.: Pyrolysis.

\begin{tabular}{|c|c|c|c|c|c|c|}
\hline Process path & Economic factor & Environmental factor & TRL factor & Total Profit ( $€ /$ ton of waste) & GPI & Global position \\
\hline Pyro. $740^{\circ} \mathrm{C}+\mathrm{S}$ & 0.99 & 1.00 & 0.56 & 373.5 & 448.3 & 1 \\
\hline Pyro. $1000^{\circ} \mathrm{C}+$ S. + P. & 1.00 & 0.49 & 0.56 & 243.9 & 185.4 & 2 \\
\hline Pyro. $1000^{\circ} \mathrm{C}+\mathrm{S}$. & 0.99 & 0.49 & 0.56 & 240.8 & 184.4 & 3 \\
\hline Mechanical Recycling & 0.98 & 0.27 & 0.89 & 175.6 & 143.9 & 4 \\
\hline Direct Downcycling & 0.70 & 0.23 & 1.00 & 0.0 & 70.6 & 5 \\
\hline Incineration & 0.79 & 0.00 & 1.00 & -3.3 & 0.0 & 6 \\
\hline Landfilling & 0.00 & 0.11 & 1.00 & -437.8 & 0.0 & 7 \\
\hline
\end{tabular}

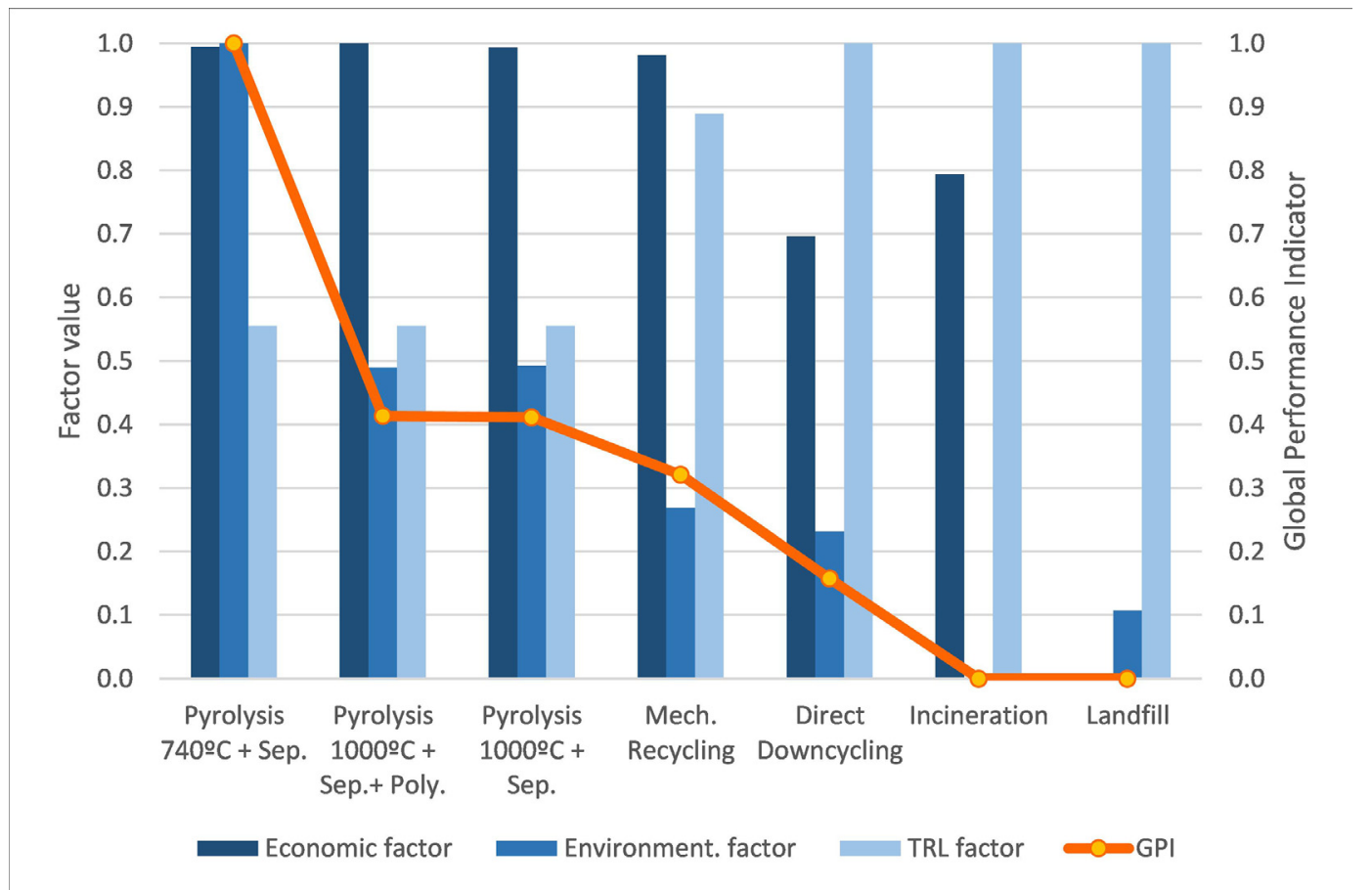

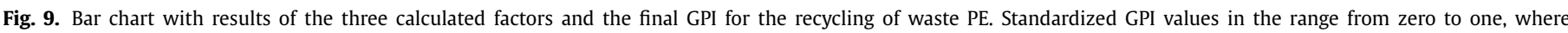
one corresponds to the highest value. Sep.: Separation, Poly.: Polymerization, Mech.: Mechanical. 


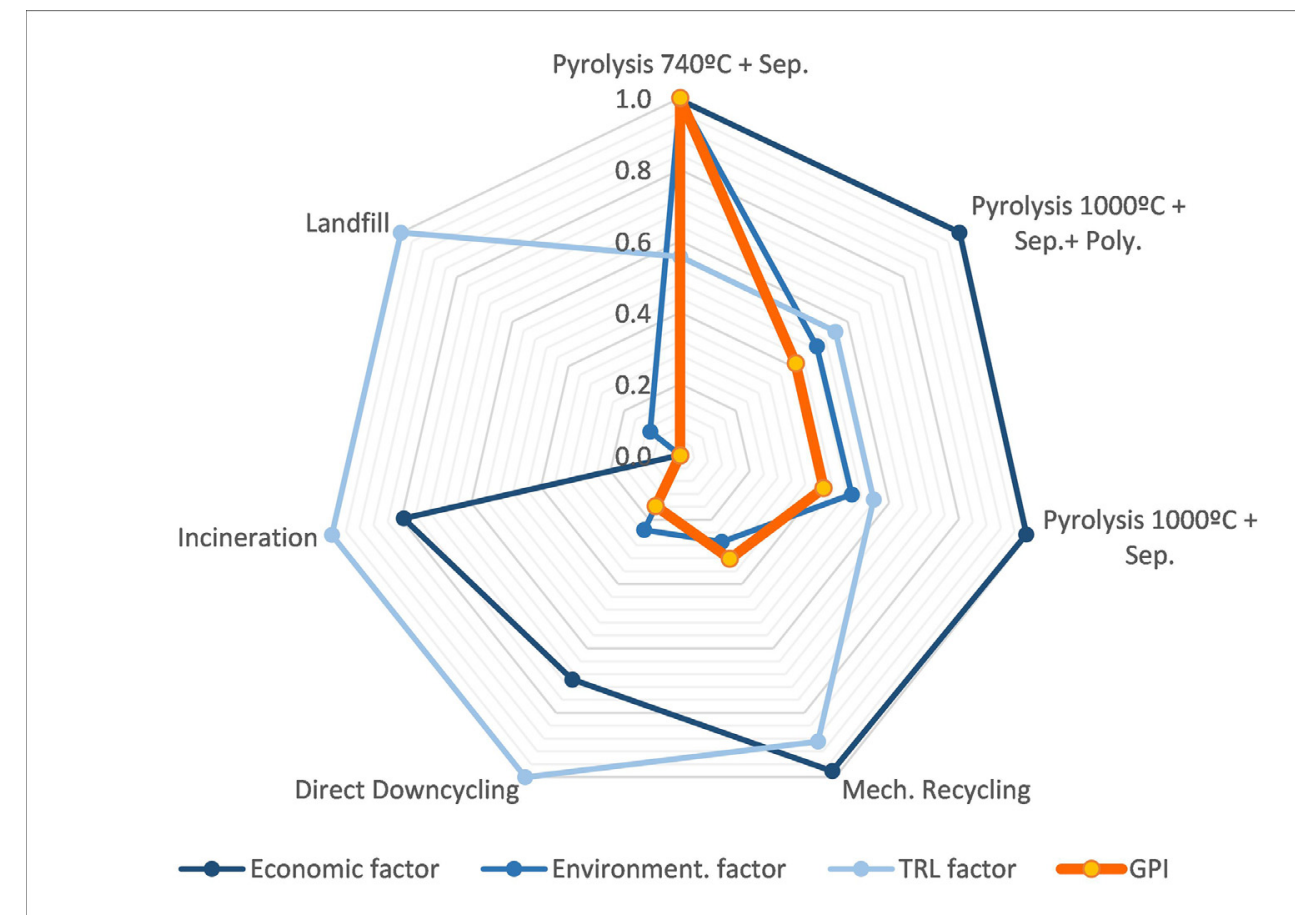

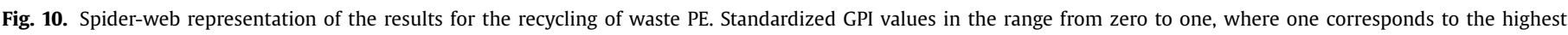
value. Sep.: Separation, Poly.: Polymerization, Mech.: Mechanical.

Table 4

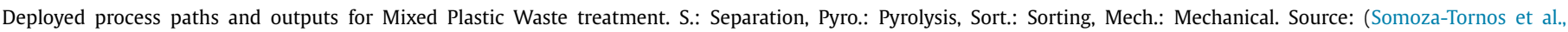
2021).

\begin{tabular}{|c|c|c|}
\hline Path & Processes & Outputs \\
\hline 1 & Landfilling MPW & None. \\
\hline 2 & Incineration MPW & Energy recovery. \\
\hline 3 & Downcycling MPW & MP Waste. \\
\hline 4 & Sorting + Downcycling all & PE, PP, PET \& PS wastes. \\
\hline 5 & Pyrolysis MPW + Sep. & Butane, ethylene, propylene, propane, hydrogen, methane, ethane, ethylbenzene, styrene, benzene $\&$ toluene. \\
\hline 6 & Sort. + Mech. Recycling all & Recycled grade PE, PP, PS \& PET. \\
\hline 7 & Sort. + Pyro.PE $1000^{\circ} \mathrm{C}+\mathrm{S}$. & Butadiene, benzene, ethylene, methane, propylene \& PP, PET, PS wastes. \\
\hline 8 & Sort. + Pyro.PE $740^{\circ} \mathrm{C}+\mathrm{S}$. & Ethylene, ethane, methane, propylene, pyrene, benzene, toluene \& PP, PET, PS wastes. \\
\hline 9 & Sort. + Pyro.PP $760^{\circ} \mathrm{C}+\mathrm{S}$. & Ethane, methane, propylene, ethylene, benzene, toluene, naphthalene \& PE, PET, PS wastes. \\
\hline 10 & Sort. + Pyro.PS $425^{\circ} \mathrm{C}+\mathrm{S}$. & Ethylbenzene, cumene, toluene, triphenylbenzene \& PP, PET, PE wastes. \\
\hline 11 & Sort. + Incineration PET & Energy recovery \& PE, PP, PS wastes. \\
\hline
\end{tabular}

Table 5

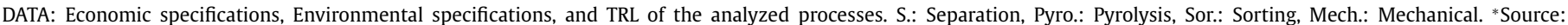
(Somoza-Tornos et al., 2021).

\begin{tabular}{|c|c|c|c|c|c|c|c|c|c|}
\hline \multirow[b]{2}{*}{ Process path } & \multicolumn{4}{|c|}{ Economic specifications ( $€ /$ ton of waste)* } & \multicolumn{4}{|c|}{ Environmental Value ( $€$ /ton of waste)* } & \multirow{2}{*}{$\begin{array}{l}\text { TRL } \\
\text { Value }\end{array}$} \\
\hline & Total cost & Waste purchase & Products value & Profit & Process & Feed & Products & Profit & \\
\hline Direct Downcycling & 0.0 & 306.0 & 306.0 & 0.0 & 0.0 & 48.8 & 48.8 & 0.0 & 9 \\
\hline Sor. + Pyro. $740^{\circ} \mathrm{C}+\mathrm{S}$. & 448.9 & 306.0 & 558.3 & -196.6 & 77.1 & 48.8 & 311.8 & 185.9 & 5 \\
\hline Pyro. MPW $600^{\circ} \mathrm{C}+\mathrm{S}$. & 255.9 & 306.0 & 511.6 & -50.3 & 109.0 & 48.8 & 164.5 & 6.6 & 5 \\
\hline Sor. + Pyro. $1000^{\circ} \mathrm{C}+\mathrm{S}$ & 447.6 & 306.0 & 570.9 & -182.6 & 78.4 & 48.8 & 156.0 & 28.7 & 5 \\
\hline Sor. + Mech.Recycling & 421.2 & 306.0 & 547.3 & -179.9 & 129.6 & 48.8 & 148.0 & -30.5 & 8 \\
\hline Sor. + Pyro. $760^{\circ} \mathrm{C}+\mathrm{S}$. & 330.8 & 306.0 & 356.8 & -279.9 & 28.2 & 48.8 & 147.4 & 70.4 & 5 \\
\hline Sorting + Downcycling & 314.6 & 306.0 & 330.6 & -290.0 & 13.6 & 48.8 & 49.2 & -13.3 & 8 \\
\hline Sor. + Incineration PET & 330.6 & 306.0 & 333.0 & -303.6 & 42.7 & 48.8 & 47.9 & -43.6 & 9 \\
\hline Sor. + Pyro $.425^{\circ} \mathrm{C}+\mathrm{S}$. & 333.8 & 306.0 & 306.0 & -333.8 & 20.5 & 48.8 & 68.2 & -1.2 & 5 \\
\hline Incineration MPW & 128.2 & 306.0 & 450.0 & 15.8 & 193.8 & 48.8 & 148.2 & -94.5 & 9 \\
\hline Landfill MPW & 97.5 & 306.0 & 0.0 & -403.5 & 17.8 & 48.8 & 0.0 & -66.7 & 9 \\
\hline
\end{tabular}

\subsection{Environmental performance assumptions}

The environmental impacts of the feedstock, products, and processes are obtained (and eventually monetized) according to the life cycle impact analysis model ReCiPe2016 (National Institute for Public Health and the Environment, 2017). The environmental im- pact indicators are obtained from EcoInvent database version 3.4 (Wernet et al., 2016), via the life cycle assessment (LCA) software SimaPro ${ }^{\circledR}$ (Goedkoop et al., 2014). Once the environmental indicators are obtained for each process and material stream, they are monetized using environmental prices for midpoints as proposed in the "Environmental Prices Handbook - EU28 version" by 


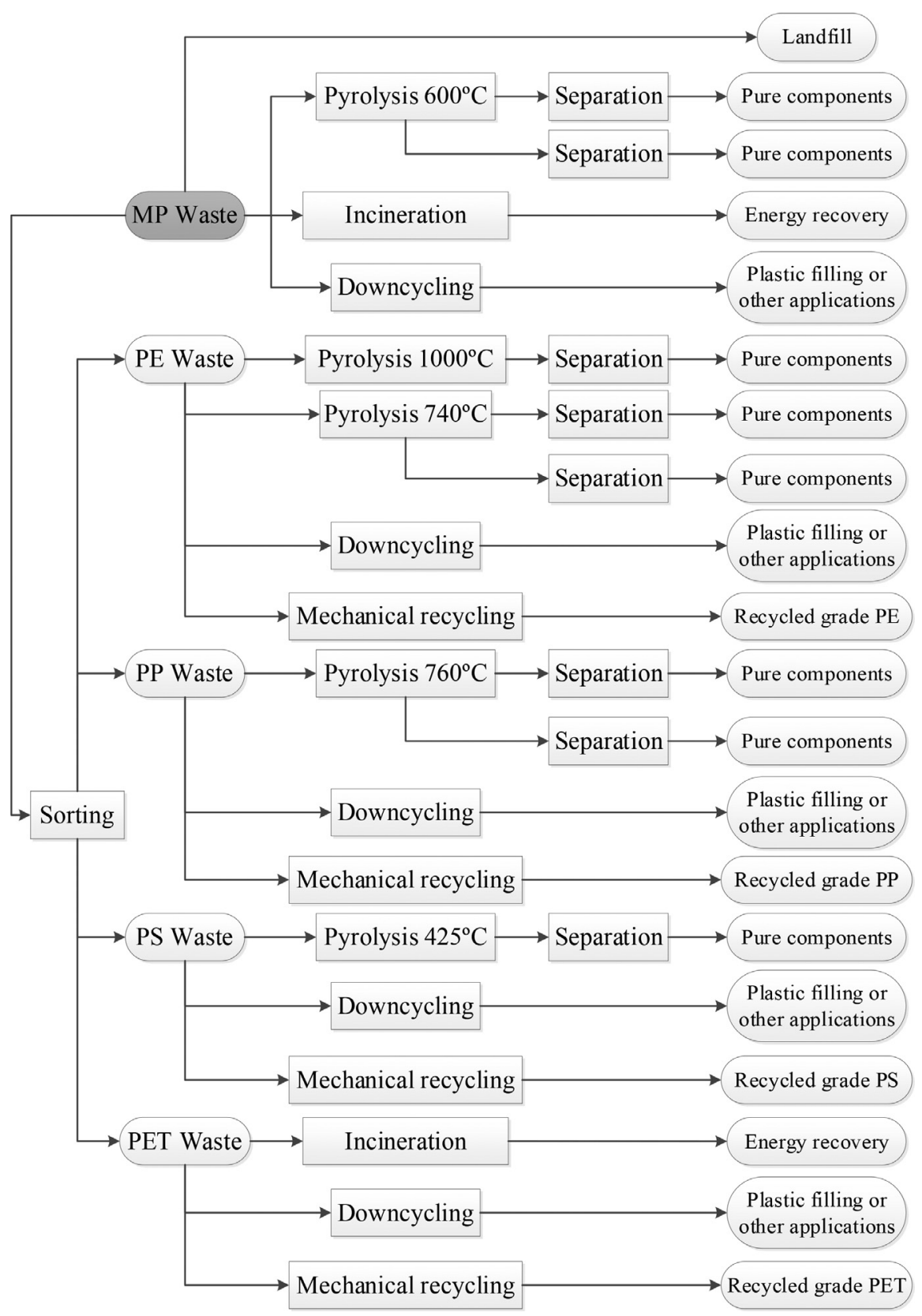

Fig. 11. Tentative paths for Mixed Plastic Waste treatment.

Table 6

Results and weighting parameters for the different process paths. S.: Separation, Pyro.: Pyrolysis, Sor.: Sorting, Mech.: Mechanical.

\begin{tabular}{|c|c|c|c|c|c|c|}
\hline Process path & Economic factor & Environmental factor & TRL factor & Total Profit ( $€ /$ ton of waste) & GPI & Global position \\
\hline Direct Downcycling & 0.96 & 0.34 & 1.00 & 0.0 & 152.5 & 1 \\
\hline Sor. + Pyro. $740^{\circ} \mathrm{C}+\mathrm{S}$. & 0.49 & 1.00 & 0.56 & -10.7 & 126.0 & 2 \\
\hline Pyro. MPW $600^{\circ} \mathrm{C}+\mathrm{S}$. & 0.84 & 0.36 & 0.56 & -43.7 & 72.0 & 3 \\
\hline Sor. + Pyro. $1000^{\circ} \mathrm{C}+\mathrm{S}$ & 0.53 & 0.44 & 0.56 & -153.9 & 40.7 & 4 \\
\hline Sor. + Mech.Recycling & 0.53 & 0.23 & 0.89 & -210.4 & 28.1 & 5 \\
\hline Sor. + Pyro. $760^{\circ} \mathrm{C}+\mathrm{S}$. & 0.29 & 0.59 & 0.56 & -209.5 & 25.1 & 6 \\
\hline Sorting + Downcycling & 0.27 & 0.29 & 0.89 & -303.3 & 11.6 & 7 \\
\hline Sor. + Incineration PET & 0.24 & 0.18 & 1.00 & -347.2 & 5.3 & 8 \\
\hline Sor. + Pyro $425^{\circ} \mathrm{C}+\mathrm{S}$. & 0.17 & 0.33 & 0.56 & -335.0 & 4.2 & 9 \\
\hline Incineration MPW & 1.00 & 0.00 & 1.00 & -78.7 & 0.0 & 10 \\
\hline Landfill MPW & 0.00 & 0.10 & 1.00 & -470.2 & 0.0 & 11 \\
\hline
\end{tabular}


de Bruyn et al. (2018). Data and results from LCA were adapted from Somoza-Tornos et al. (2021).

The EcoInvent database provides life cycle impacts for these processes from a cradle-to-gate perspective. The burden of mechanical recycling is estimated to be proportional to the burden of producing fresh material via polymerization (Andreoni et al., 2015). In particular, burdens are scaled as proportional to the energy consumption of both processes, which is $87 \%$ lower for recycling. Furthermore, mechanical recycling results in a reduction in the demand of virgin polymer granulate, which is accounted for within the system boundaries (Somoza-Tornos et al., 2020a).

\subsection{Process maturity assumptions}

The maturity of the technologies is assessed through their TRL, which is defined in the EU Horizon 2020 Work Programme (European Commission, 2017).

\subsection{Economic performance assumptions}

Total costs are calculated or estimated on a unitary basis (i.e. per $\mathrm{kg}$ of treated waste). To do this, estimated capital investment costs are annualized considering a linear depreciation of 10 years, 330 yearly operational days, and a fixed depreciation rate of $15 \%$. Operational costs are also estimated yearly and then both are added up to obtain a total production annual cost, which is converted to unitary costs dividing by the annual waste treatment capacity. The data and procedure for these estimations are taken from Somoza-Tornos et al. (2021, 2020b), where the cost estimation is based on Sinnott and Towler (2020).

\section{Results and discussion}

Using the information available in the ontology and considering all assumptions previously described, all suitable paths have been built for the two presented case studies. Those selected for recycling polyethylene waste are schematized in Fig. 8, while the potential alternatives foreseen for the extended case study (management of mixed plastic waste) have been summarized in Fig. 11.

\subsection{Illustrative case study: PE waste recycling}

In order to limit the scope of this illustrative case study, some basic constraints in the processing path generation step have been accepted (e.g.: assuming that intermediate products, which are usually pyrolysis gases and oils, are fully separated).Seven potential structures have been identified, which can be further clustered based on their main processing steps (Table 1).

Economic and environmental values of the processes are calculated and TRL values defined. They are sorted out from the most profitable economically and environmentally to the less, as shown in Table 2, in accordance with the GPI. The GPI is calculated with the economic and environmental profits and the three factors, as explained in section 3 and shown below in Table 3; note that the total profit is standardized before the application of the Eq. (9) to avoid negative values in the GPI Results are graphically represented in Figs. 9 and 10.

Based on these results, the most economically profitable process would include a pyrolysis at $1000^{\circ} \mathrm{C}$, along with the separation of the resulting gas and oil fractions in each case and the consequent polymerization of ethylene into polyethylene. It is closely followed by two other pyrolysis-based paths and then by the mechanical recycling option while landfilling is found to be the less profitable option.

Concerning the environmental profit, the highest value corresponds to Pyrolysis at $740^{\circ} \mathrm{C}$ with a noteworthy difference compared to the second and third, which correspond to the two paths involving pyrolysis at $1000^{\circ} \mathrm{C}$. The significant difference stems mostly from the environmental price of the products obtained on each path. Indeed, the main products in pyrolysis at $740^{\circ} \mathrm{C}$ are methane and benzene, whose environmental values are considerably higher than the ones corresponding to the main products of

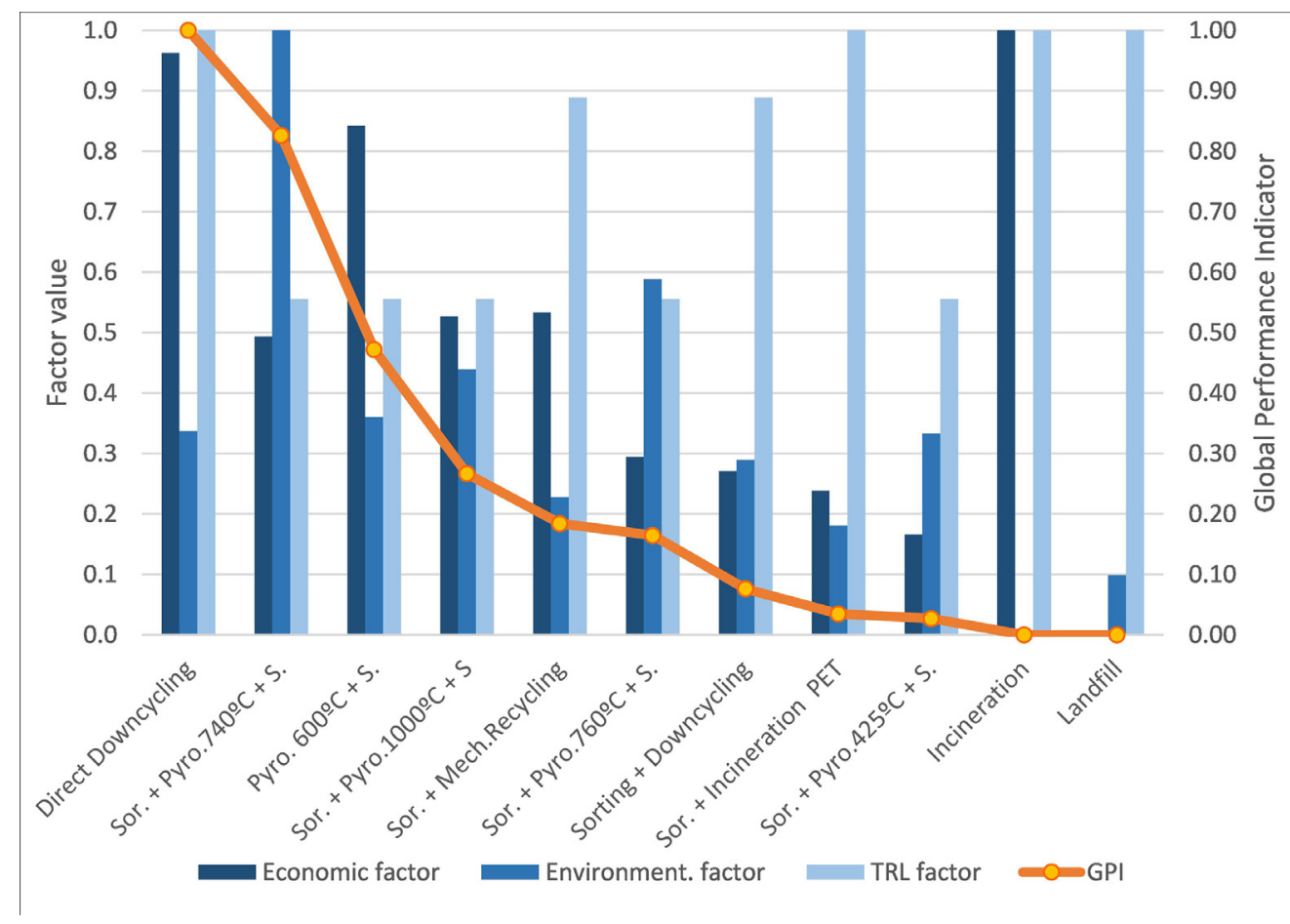

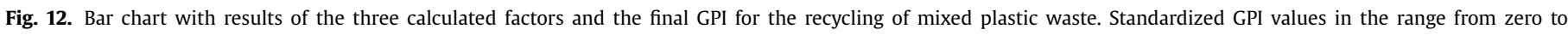
one, where one corresponds to the highest value. S.: Separation, Pyro.: Pyrolysis, Sor.: Sorting, Mech.: Mechanical. 
any other path. On the other end of the spectrum, the lowest environmental performance corresponds to incineration and landfilling.

The most mature processes are the traditional end-of-life alternatives such as incineration, landfilling, and downcycling. In contrast, the least developed are the pyrolysis paths since they are not as commonly used as the conventional ones at the industrial scale level.

Regarding the GPI, the alternative with the highest value, with a tangible difference, is the pyrolysis at $740^{\circ} \mathrm{C}$ that, despite its lower TRL, has a high economic profit margin and significantly high environmental profit; the two paths based on pyrolysis at $1000^{\circ} \mathrm{C}$ are also worth considering. By contrast, the lowest GPI corresponds to landfilling because of its very low economic and environmental performances, followed by incineration owing to its low environmental performance.

The substantial difference between pyrolysis at $740^{\circ} \mathrm{C}$ and the rest is due not only to the fact that it has the highest sum of environmental and economic profits, but also to the multiplying effect of the factors that maximize gaps between alternatives.

We can conclude this discussion by stating that, since the three pyrolysis paths and mechanical recycling have very similar economic profits and TRLs, it is not evident which upcycling/recycling alternative would be best to manage the available waste materials. This is a usual case, and the difference in the environmental value of each process and its products, as well as the technological maturity of the involved processes, are used to tip the balance in favor of one or the other.

\subsection{Extended case study: MPW waste recycling}

For the extended case study, also assuming some path generation constraints, there are 11 tentative paths for the conversion of MPW (see Fig. 11). Note that, although the number of possible combinations is much higher (around 30), only the most relevant ones are shown; in this sense the routes involving the polymerization step have been omitted in this figure since they do not show a great advantage against those without it (Tables 2 and 3). In addition and for simplicity purposes, the process parameters and colorcoded path shadows are not shown in Fig. 11. Table 4 shows all deployed paths and their corresponding products. Economic and environmental parameters of the processes are calculated and shown in Table 5, together with the estimated TRL values. The calculated GPI, along with the three factors, are shown in Table 6; note that, again, the total profit is standardized before the application of the Eq. (9) to avoid negative values in the GPI Results are graphically represented in Figs. 12 and 13. Finally, in this case, we have considered that, when one of the sorted plastics paths is chosen, the other sorted plastics are sent directly to downcycling, but many other possible combinations could be also considered (e.g. they could be incinerated, landfilled, pyrolyzed, mechanically recycled and all the possible combinations among them). Note that some paths were omitted, for example sorting followed by incineration or landfilling of sorted plastics, since they would offer evident disadvantages against unsorted MPW incineration or landfilling.

In this extended case study, we can appreciate that total profits (economic and environmental) are much lower than in the illustrative case study and that all of them are negative, which means they are not globally profitable taking into account both economic and environmental parameters. This is due not only to the cost added by the sorting process but also to the lower amount of material to be treated afterward, hence the lower amounts of final products, which yield lower revenues. For instance, in the illustrative case study, we were managing $100 \%$ of the purchased waste (PE waste in that case) and obtaining certain amounts of marketable products. However, in this case, after sorting, only around $60 \%$ of the purchased mixed plastic waste is finally available to be treated through the PE path, which yields lower amounts of marketable products. The remaining $40 \%$ is made of other kinds of

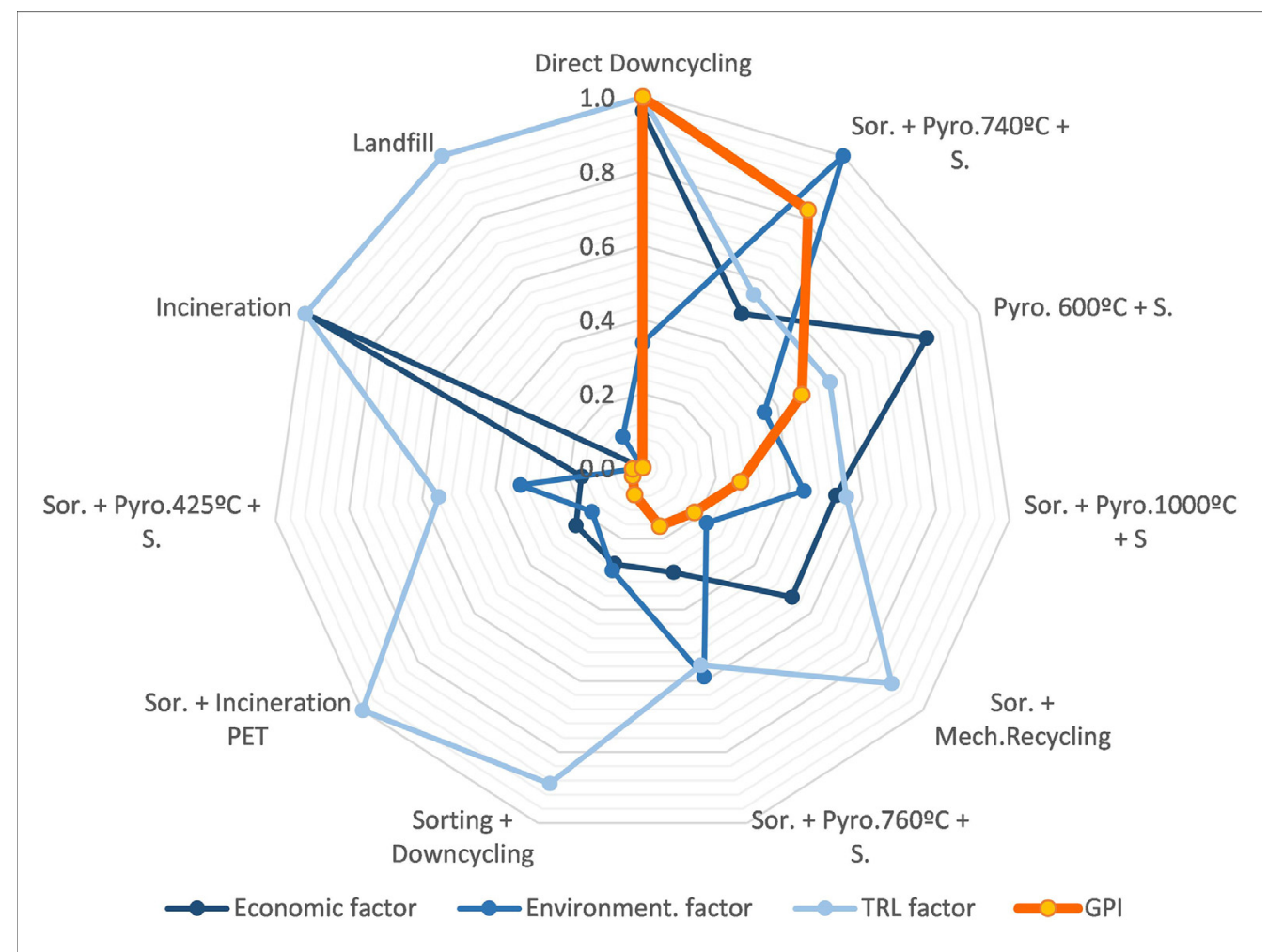

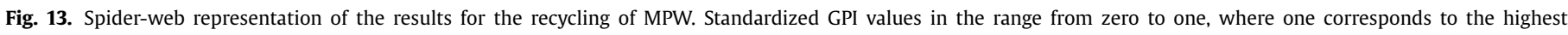
value. S.: Separation, Pyro.: Pyrolysis, Sor.: Sorting, Mech.: Mechanical. 
plastic waste, which are assumed to be sold for downcycling, and other not recoverable waste that should be incinerated or treated in some other way.

Among the overall set of alternatives, we find MPW incineration and downcycling as the ones with better economic performance, followed by MPW pyrolysis at $600^{\circ} \mathrm{C}$, with the lowest economic loss. In environmental regards, sorting followed by pyrolysis of $\mathrm{PE}$ at $740^{\circ} \mathrm{C}$ along with the downcycling of the other sorted plastic wastes is, by far, the most environmentally friendly option.

According to TRL, analogically to the illustrative case study presented above, the traditional end-of-life alternatives are the ones with the highest values, namely downcycling, incineration, and landfilling. Based on the GPI, MPW downcycling seems to be the best option, followed by $\mathrm{PE}$ pyrolysis at $740^{\circ} \mathrm{C}$, MPW pyrolysis at $600^{\circ} \mathrm{C}$, and PE pyrolysis at $1000^{\circ} \mathrm{C}$; on the other hand, MPW incineration and landfilling appear to be the less promising alternatives.

As predicted, chemical recycling appears to be a very promising way of treating waste and closing the materials loop, thus obtaining exploitable resources that can potentially be used instead of fresh raw materials. Additionally, these processes are economically and environmentally far more profitable than the traditional ways of treating this kind of waste, namely landfill or incineration.

\section{Conclusions}

The growing application of circular economy principles entails the emergence of new waste-to-resource technologies, such as chemical recycling. This work presents a methodology for the systematic generation of a list of potential waste-to-resource transformation paths, based on the use of ontologies. Thanks to this method, new paths including these new technologies can be systematically identified, combined with other well-established technologies (including end-of-life alternatives), and compared. By doing so, a manageable list of potentially efficient processes can be obtained for further optimization through currently available superstructure analysis systematics, as well as a more in-depth development. Hence, it aids engineering analysis and decisionmaking for the identification of new unveiled process combinations and allows the reduction of the number of alternatives to the most promising ones by removing those that are less suitable according to economic, environmental, and maturity aspects.

This method allows a pre-selection of a limited number of relevant technologies to treat any kind of waste among a wide range of alternatives. Thus, it is useful when the number of alternatives to analyze is unreachable by manual procedures or to reveal new tentative processes that would not be considered or discovered by traditional methods. Although the assessment performed with this method is not exhaustive but simplified, it can be a useful tool to perform a pre-screening of alternatives before further and more detailed analysis.

A fair evaluation of the potential technologies has to consider their maturity, as the application of technologies with lower TRL values is riskier to implement than traditional alternatives. As a result, the proposed GPI includes a factor to assess the maturity of the technology. Considering environmental and economic profit with equivalent importance is an interesting approach, not only to balance both objectives but also for discriminating between economically similar alternatives. The methodological framework presented also allows the generation of routes based on linking consecutive processes in a linking-blocks approach. This method leads to flexible product compositions, aiding decision-makers to identify the most economically and environmentally beneficial solutions.

To ensure that the list of alternatives includes the most up-todate transformation technologies, future work will address the development of procedures for the systematic search and implementation of waste-to-resource processes into the ontological frame- work. When a thorough analysis and optimization of some of the proposed alternatives is carried out, the results and conditions obtained should be updated or reintroduced in the ontology to keep it updated and consider new optimized alternatives in future cases or implementations. It is useful as well to keep new information in the ontology since it is an efficient knowledge management tool, where information is taxonomically organized and available for future developments or inquiries. Therefore, the ontology is considered as an incremental tool, which will be gaining value and usability with the addition of new processes. The final goal of this ontology is to hold as many processes specifications as possible so that, along with the algorithm, would be able to provide a set of arranged alternatives to any transformation process taking into account several objectives with a global perspective.

\section{Declaration of Competing Interest}

The authors declare that they have no known competing financial interests or personal relationships that could have appeared to influence the work reported in this paper.

\section{CRediT authorship contribution statement}

Adrián Pacheco-López: Conceptualization, Methodology, Software, Data curation, Writing - original draft, Writing - review \& editing, Visualization. Ana Somoza-Tornos: Conceptualization, Methodology, Software, Writing - original draft. Moisès Graells: Validation, Writing - original draft, Supervision, Project administration, Funding acquisition. Antonio Espuña: Conceptualization, Writing - original draft, Writing - review \& editing, Supervision, Project administration, Funding acquisition.

\section{Acknowledgments}

Financial support received from the Spanish Economic Matters and Digital Transition Ministry (MINECO) and the European Regional Development Fund, both funding the research Projects AIMS (DPI2017-87435-R) is fully acknowledged. Adrian Pacheco-Lopez thankfully acknowledges the financial support received from the Spanish Ministry of Science and Innovation (grant ref. PRE2018087135).

\section{Supplementary material}

The Supplementary Material for this article can be found online at: https://cepima.upc.edu/en/contributions/saw2reroce.

\section{References}

Al-Salem, S.M., Antelava, A., Constantinou, A., Manos, G., Dutta, A., 2017. A review on thermal and catalytic pyrolysis of plastic solid waste (PSW). J. Environ. Manage. 197, 177-198. doi:10.1016/j.jenvman.2017.03.084.

Andreoni, V., Saveyn, H.G.M., Eder, P., 2015. Polyethylene recycling: Waste policy scenario analysis for the EU-27. J. Environ. Manage. 158, 103-110. doi:10.1016/j. jenvman.2015.04.036.

Bechhofer, S., Harmelen, F. Van, Hendler, J., Horrocks, I., McGuinness, D.L., PatelSchneider, P.F., Stein, L.A., 2004. Owl web ontology language reference [WWW Document]. W3C Recomm. URL https://www.w3.org/TR/owl-ref/.

Boix, M., Montastruc, L., Azzaro-Pantel, C., Domenech, S., 2015. Optimization methods applied to the design of eco-industrial parks: a literature review. J. Clean Prod. 87, 303-317. doi:10.1016/j.jclepro.2014.09.032.

Borst, P., Akkermans, H., Top, J., 1997. Engineering ontologies. Int. J. Hum. Comput. Stud. 46, 365-406. doi:10.1006/ijhc.1996.0096.

Cecelja, F., Trokanas, N., Raafat, T., Yu, M., 2015. Semantic algorithm for industrial symbiosis network synthesis. Comput. Chem. Eng. 83, 248-266. doi:10.1016/j. compchemeng.2015.04.031.

Corcho, O., Fernández-López, M., Gómez-Pérez, A., 2006. Ontological engineering: principles, methods, tools and languages. In: Ontologies for Software Engineering and Software Technology. Springer, Berlin Heidelberg, pp. 1-48. doi:10.1007| 3-540-34518-3_1. 
de Bruyn, S., Bijleveld, M., de Graaff, L., Schep, E., Schroten, A., Vergeer, R., Ahdour, S., 2018. Environmental Prices Handbook - EU28 version. Delft, CE Delft, Oct. 2018 Publ. code 18.7N54.125.

Ellen MacArthur Foundation, 2017. The New Plastics Economy: Rethinking the Future of Plastics \& Catalysing Action. Ellen MacArthur Found, p. 68.

European Commission, 2017. EN HORIZON 2020 WORK PROGRAMME 2016 -2017 20 . General Annexes. European Commission Decision C (2017) 2468 of 24 April 2017), Annex G, Technology Readiness Levels (TRL) 1-39.

Eurostat - European Commission, 2020. Packaging waste statistics. https://ec.europa. eu/eurostat/statistics-explained/index.php/Packaging_waste_statistics.

Glimm, B., Horrocks, I., Motik, B., Stoilos, G., Wang, Z., 2014. HermiT: an OWL 2 reasoner. J. Autom. Reason. 53, 245-269. doi:10.1007/s10817-014-9305-1.

Goedkoop, M., Ponsioen, T., Meijer, E., 2014. Introduction to LCA with SimaPro.

Gruber, T.R., 1995. Toward principles for the design of ontologies used for knowledge sharing. Int. J. Hum. - Comput. Stud. 43, 907-928. doi:10.1006/ijhc.1995. 1081.

Gu, D., Jiang, J., Zhang, Y., Sun, Y., Jiang, W., Du, X, 2020. Concern for the future and saving the earth: when does ecological resource scarcity promote pro-environmental behavior? J. Environ. Psychol. 72, 101501. doi:10.1016/j.jenvp. 2020.101501.

Jeswani, H., Krüger, C., Russ, M., Horlacher, M., Antony, F., Hann, S., Azapagic, A., 2021. Life cycle environmental impacts of chemical recycling via pyrolysis of mixed plastic waste in comparison with mechanical recycling and energy recovery. Sci. Total Environ., 144483 doi:10.1016/j.scitotenv.2020.144483.

Kaminsky, W., Predel, M., Sadiki, A., 2004. Feedstock recycling of polymers by pyrolysis in a fluidised bed. Polym. Degrad. Stab. 85, 1045-1050. doi:10.1016/j. polymdegradstab.2003.05.002.

Kondili, E., Pantelides, C.C., Sargent, R.W.H., 1993. A general algorithm for shortterm scheduling of batch operations-I. MILP formulation. Comput. Chem. Eng. 17, 211-227. doi:10.1016/0098-1354(93)80015-F.

Lamy, J.-B., 2017. Owlready: ontology-oriented programming in Python with automatic classification and high level constructs for biomedical ontologies. Artif. Intell. Med. 80, 11-28. doi:10.1016/j.artmed.2017.07.002.

Marquardt, W., Morbach, J., Wiesner, A., Yang, A., 2010. OntoCAPE-A Re-Usable Ontology for Chemical Process Engineering, RWTHedition. Springer Berlin Heidelberg, Berlin, Heidelberg doi:10.1007/978-3-642-04655-1.

Martín, A.J., Mondelli, C., Jaydev, S.D., Pé Rez-Ramírez, J., 2020. Catalytic processing of plastic waste on the rise. Chempr 0, 1-47. doi:10.1016/j.chempr.2020.12.006.

Morbach, J., 2009. OntoCAPE-A (re)usable Ontology For Computer-Aided Process Engineering. Comput. Chem. Eng.. RWTH Aachen University.

Morbach, J., Wiesner, A., Marquardt, W., 2009. OntoCAPE-A (re)usable ontology for computer-aided process engineering. Comput. Chem. Eng. 33, 1546-1556. doi:10.1016/j.compchemeng.2009.01.019.

Musen, M.A., 2015. The Protégé project: a look back and a look forward. AI Matters. Assoc. Comput. Mach. Specif. Interes. Gr. Artif. Intell. 1, 4-12. doi:10.1145/ 2757001.2757003.

National Institute for Public Health and the Environment, 2017. ReCiPe 2016 v1.1. RIVM Rep. 2016-0104 201.

Onwudili, J.A., Insura, N., Williams, P.T., 2009. Composition of products from the pyrolysis of polyethylene and polystyrene in a closed batch reactor: effects of temperature and residence time. J. Anal. Appl. Pyrolysis 86, 293-303. doi:10. 1016/j.jaap.2009.07.008
Onwudili, J.A., Muhammad, C., Williams, P.T., 2019. Influence of catalyst bed temperature and properties of zeolite catalysts on pyrolysis-catalysis of a simulated mixed plastics sample for the production of upgraded fuels and chemicals. J. Energy Inst. 92, 1337-1347. doi:10.1016/j.joei.2018.10.001.

Paslaru-Bontas, E., 2007. A Contextual Approach to Ontology Reuse: Methodology, Methods and Tools for the Semantic Web. PhD Thesis. FU Berlin. Freien Universit"at Berlin.

PlasticsEurope, 2020. Plastics - the Facts 2020. Brussels.

Raafat, T., Trokanas, N., Cecelja, F., Bimi, X., 2013. An ontological approach towards enabling processing technologies participation in industrial symbiosis. Comput. Chem. Eng. 59, 33-46. doi:10.1016/j.compchemeng.2013.03.022.

RWTH Aachen University, 2016. OntoCAPE Material [WWW Document]. URL https: //www.avt.rwth-aachen.de/Ontocape (accessed 1.6.20).

Singh, N., Hui, D., Singh, R., Ahuja, I.P.S., Feo, L., Fraternali, F., 2017. Recycling of plastic solid waste: a state of art review and future applications. Compos. Part B Eng. 115, 409-422. doi:10.1016/j.compositesb.2016.09.013.

Sinnott, R., Towler, G., 2020. Costing and project evaluation, in: chemical engineering design. pp. 275-369. doi:10.1016/b978-0-08-102599-4.00006-0.

Solis, M., Silveira, S., 2020. Technologies for chemical recycling of household plastics - a technical review and TRL assessment. Waste Manag doi:10.1016/j.wasman. 2020.01.038.

Somoza-Tornos, A., Espuña, A., Graells, M., 2020a. Doctoral Thesis: Decision Support Strategies for the Efficient Implementation of Circular Economy Principles in Process Systems. Cent. Environ. Process Eng. Polytechnical University of Catalonia.

Somoza-Tornos, A., Gonzalez-Garay, A., Pozo, C., Graells, M., Espuña, A., GuillénGosálbez, G., 2020b. Realizing the potential high benefits of circular economy in the chemical industry: ethylene monomer recovery via polyethylene pyrolysis. ACS Sustain. Chem. Eng. 8, 3561-3572. doi:10.1021/acssuschemeng. 9 b04835.

Somoza-Tornos, A., Pozo, C., Graells, M., Espuña, A., Puigjaner, L., 2021. Process screening framework for the synthesis of process networks from a circular economy perspective. Resour. Conserv. Recycl. 164, 105147. doi:10.1016/j. resconrec.2020.105147.

Studer, R., Benjamins, V.R., Fensel, D., 1998. Knowledge engineering: principles and methods. Data Knowl. Eng. 25, 161-197. doi:10.1016/S0169023X(97)00056-6.

Van Rossum, G., Drake, F.L., 2009. Python 3 Reference Manual. CreateSpace, Scotts Valley, CA.

W3C OWL Working Group, 2012. OWL 2 Web Ontology Language Document Overview. OWL 2 Web Ontol. Lang, pp. 1-7.

Wernet, G., Bauer, C., Steubing, B., Reinhard, J., Moreno-Ruiz, E., Weidema, B., Zah, R., Wernet wernet, G., 2016. The ecoinvent database version 3 (part I): overview and methodology. Int. J. Life Cycle Assess. 21, 1218-1230. doi:10.1007/ s11367-016-1087-8.

Yang, L., Cormican, K., Yu, M., 2019. Ontology-based systems engineering: a state-of-the-art review. Comput. Ind. 111, 148-171. doi:10.1016/j.compind.2019. 05.003.

Zhou, L., Zhang, C., Karimi, I.A., Kraft, M., 2018. An ontology framework towards decentralized information management for eco-industrial parks. Comput. Chem. Eng. 118, 49-63. doi:10.1016/j.compchemeng.2018.07.010. 